\title{
Percepção sobre o desperdício de alimentos nas escolas: um olhar sobre o município de Dom Pedrito, RS
}

\section{Perception of food waste in schools: a look at the municipality of Dom Pedrito, RS.}

Shirley Grazieli da Silva Nascimento ${ }^{1 *}$, Martita dos Santos Guimarães ${ }^{1}$, Mariana Rockenbach de Ávila², Daniel Hanke¹, Cláudio Becker³, Joélio Farias Maia².

\section{RESUMO}

Utilizou-se como objetivos norteadores deste trabalho: a) Identificar as causas recorrentes que geram desperdício na alimentação escolar em escolas do município de Dom Pedrito/RS; b) Verificar como são elaborados os cardápios de alimentação servida nas escolas; c) Qual a origem dos alimentos utilizados no preparo da alimentação escolar; d) Qual o número de refeições servidas; e) Quantificar o desperdício de alimentos gerado nas escolas; f) Verificar a finalidade dada aos resíduos e as sobras limpas e g) Averiguar a percepção dos educandos sobre a alimentação escolar servida na escola. O universo de estudo é um município do interior do Rio Grande do Sul denominado Dom Pedrito, localizado na Região da Campanha. Como técnica de coleta de dados foi utilizado um roteiro com questões fechadas e questões abertas, que abordou a percepção e comportamento dos educandos em relação a alimentação e desperdício de alimentos na alimentação escolar. O tema voltado para o desperdício de alimentos não envolve apenas o custo, mas também questões socioambientais e políticas. Em suma, foi possível observar que nas escolas municipais de Dom Pedrito - RS, as diretoras e merendeiras têm consciência e evitam o desperdício de alimentos.

Palavras-chave: Alimentação saudável; Sistema alimentar; Rendimento escolar.

\begin{abstract}
It was used as guiding objectives of this work: a) Identify the recurrent causes that generate waste in school meals in schools in the city of Dom Pedrito/RS; b) Check how menus for food served in schools are prepared; c) What is the origin of the foods used in the preparation of school meals; d) What is the number of meals served; e) Quantify food waste generated in schools; f) Check the purpose given to the waste and clean leftovers and g) Check the perception of students about the school meals served at school. The universe of study is a municipality in the interior of Rio Grande do Sul called Dom Pedrito, located in the Campanha Region. As a data collection technique, a script with closed questions and open questions was used, which addressed the perception and behavior of students in relation to food and food waste in school meals. The theme focused on food waste does not only involve cost, but also socio-environmental and political issues. In short, it was possible to observe that in municipal schools in Dom Pedrito - RS, principals and lunch ladies are aware of and avoid wasting food.
\end{abstract}

Keywords: Healthy eating; Food system; School performance.

\footnotetext{
${ }^{1}$ Universidade Federal do Pampa, UNIPAMPA. Dom Pedrito, RS

* E-mail: shirleynascimento@ unipampa.edu.br

${ }^{2}$ Embrapa Clima Temperado, Pelotas, RS - CEP: 96010-971.

${ }^{3}$ Universidade Estadual do Rio Grande do Sul, UERGS. Santana do Livramento, RS
} 


\section{INTRODUÇÃO}

É notável que na última década aumentou substancialmente a preocupação com a qualidade das refeições escolares. Assunto amplamente debatido na atualidade, a segurança alimentar tem afetado populações em todo mundo (NASCIMENTO et al., 2019). No que tange a produção de alimentos, ressalta-se que o Brasil mantém tanto na agricultura quanto na pecuária, destaque mundial na produção. No entanto, o acesso a essa produção é um dos fatores que podem diminuir ou encerrar a perspectiva de vulnerabilidade (MEDEIROS, 2018). Juntamente com a má distribuição de alimentos ocorre outro ponto preocupante, onde na maioria dos casos é desprezado, que é o desperdício de alimentos (MONTEIRO, 2013).

Um dos parâmetros da qualidade de uma unidade de nutrição e alimentação (UAN) são os desperdícios alimentares, inclusive contabilizar os custos envoltos no desperdício de alimentos amplia a compreensão do sistema alimentar e traz mais clareza para a discussão dos impactos do desperdício na sociedade (TONHÃO et al., 2020). O desperdício envolve perdas que variam desde alimentos que não são utilizados, até preparações prontas, que não chegam a ser vendidas e/ou servidas e ainda as que sobram nos pratos dos clientes e têm como destino o lixo (CASTRO, 2003). Por isso faz-se necessário uma adequada educação nutricional, que vise ao preparo de pratos equilibrados do ponto de vista nutricional, e que evitem desperdícios. Os desperdícios em Unidades de Alimentação e Nutrição (UAN) podem ocorrer em todo o processo de produção de refeições, especialmente no armazenamento, pré-preparo, cocção e distribuição, incluindo a matéria-prima e outros recursos como água, energia e mão de obra (VAZ, 2006).

A alimentação e nutrição adequadas são condições básicas para o crescimento (BARTOLAZZE et al., 2019), desenvolvimento e saúde, sobretudo de crianças (BOITO et al., 2019), considerando ainda que, uma alimentação adequada influencia determinantemente no rendimento escolar, uma vez que favorece a capacidade de concentração do aluno. A possibilidade de enriquecimento de suas dietas, além de ampliar os aspectos nutricionais apontados, poderia ampliar as rendas dos agricultores familiares com novos produtos melhor qualificados e remunerados, sendo um ganho de diferentes vias. 
Nessa perspectiva, em 31 de março de 1955, Juscelino Kubitschek de Oliveira assinou o Decreto n. 37.106, criando a Campanha da Merenda Escolar (CME). Posteriormente, em 1979, foi denominado Programa Nacional de Alimentação Escolar (PNAE), conhecido popularmente desde então por “merenda escolar". Esse programa tem como objetivo atender às necessidades nutricionais dos estudantes, durante sua permanência em sala de aula, contribuindo para o seu crescimento, desenvolvimento, aprendizagem e rendimento escolar, bem como a formação de hábitos alimentares saudáveis (SILVA, 2016).

Embora se tenha o período da alimentação na escola como um aliado na construção de bons hábitos alimentares, este fato não se confirma, sendo em algumas situações o local em que as crianças ingerem alimentos industrializados, com baixo teor nutricional e alto teor de açucares, acarretando em desperdício dos alimentos in natura ofertados pela escola (ALTEMBURG, 2014).

Dados apresentados pela FAO apontam que 1/3 dos alimentos produzidos mundialmente são desperdiçados (UNIC, 2014). Esse dado se torna assustador quando se coloca em pauta a soberania e segurança alimentar dos países. No caso brasileiro os números chegam a 39 mil toneladas por dia de desperdício ao mesmo passo em que Brasil produz $25,7 \%$ a mais do que necessitaria para alimentar sua população (BRASIL, 2013). Esse trabalho está de acordo com alguns dos Objetivos de Desenvolvimento Sustentável (ODS) da Organização das Nações Unidas (ONU), como por exemplo, o objetivo número 2 (dois) "Fome Zero e agricultora sustentável" e o número 12 (doze) "Consumo e produção responsáveis".

Como relata Sanches e Salla (2010, p. 4):

Para tentar combater o desperdício antes de mais nada é necessário ter consciência que ele existe. Conscientizar as pessoas sobre os vários tipos de desperdícios existentes é o primeiro passo a se dar quando queremos reduzir os mesmos, seja no ambiente escolar ou em qualquer outro. O primeiro passo para conscientização é observar, como agir? É necessário buscar formas de educar a sociedade na esperança de reduzir aquilo que tanto a prejudica, esta educação pode ser feita de forma oral, visual, entre outras.

O interesse pelo tema surgiu da necessidade de avaliar a aceitação da alimentação escolar versus o desperdício alimentar em escolas públicas do ensino fundamental no município de Dom Pedrito/RS. Os dados coletados nesse estudo foram úteis para identificar as possíveis causas do desperdício além de servir como aporte para estimular futuros estudos relativo a essa temática. 
Segundo (MALUF, 2007) todas as pessoas têm direito ao acesso regular e permanente a alimentos de qualidade, em quantidade suficiente, sem comprometer o acesso a outras necessidades essenciais. Sabendo da ocorrência de fome no mundo, Insegurança Alimentar e desperdício de alimentos na Alimentação Escolar (PNAE) apresenta-se o seguinte problema de pesquisa: Há desperdício de alimentos gerado na alimentação escolar em escolas municipais de Dom Pedrito/RS?

A relevância desse tema e da abordagem proposta encontra par no fato de o desperdício de alimentos tem sido um problema sério para a sociedade (BRASIL, 2013). As mudanças ocorridas no PNAE em 2009 visavam contribuir para minimizar o desperdício ao mesmo tempo em que contribuiriam para sensibilizar as crianças e as famílias sobre a importância de comer bem, com qualidade e sem desperdícios. No entanto, este problema continua no bojo das discussões sobre soberania alimentar e nutricional. As escolas continuam gerando altos índices de desperdícios de alimentos, os setores de alimentação escolar seguem com dificuldades para regionalizar os cardápios (VENTURA, 2017). Sendo assim, entender in loco essa situação pode contribuir para elucidar lacunas e trazer avanços para refletir sobre está temática no município de Dom Pedrito.

Para responder o problema de pesquisa utilizou-se como objetivos norteadores: a) Identificar as causas recorrentes que geram desperdício na alimentação escolar em escolas do município de Dom Pedrito/RS; b) Verificar como são elaborados os cardápios de alimentação servida nas escolas; c) Qual a origem dos alimentos utilizados no preparo da alimentação escolar; d) Qual o número de refeições servidas; e) Quantificar o desperdício de alimentos gerado nas escolas; f) Verificar a finalidade dada aos resíduos e as sobras limpas e g) Averiguar a percepção dos educandos sobre a alimentação escolar servida na escola.

\subsection{Fome no Mundo}

A fome afeta milhares de seres humanos no mundo todo.

O conceito de fome, no Brasil, utilizado por diferentes setores da população abarca desde aquela sensação fisiológica ligada à vontade de comer, conhecida de todos nós, até as formas mais brutais de violentação do ser humano, ligadas à pobreza e à exclusão social. Ver os filhos passarem fome é passar fome. Ter que se humilhar para receber uma cesta básica é passar fome. Trocar a dignidade por comida é passar fome. Ter medo de passar fome é estar cativo da fome. Estar desnutrido também é passar fome, mesmo que a causa principal não seja falta de alimento (VALENTE, 2003, p.56). 
No entanto, é de notório conhecimento público mundial que a quantidade de alimentos existente é capaz de suprir as necessidades básicas de todos os seres humanos.

Neste sentido, o problema da fome está associado a distribuição de alimentos, já que a produtividade agrícola é crescente a cada ano com o auxílio das novas tecnologias. Sendo assim, há que se considerar a má distribuição e o desperdício de alimentos como causas fundamentais para compreender a fome (MARTINS; FARIAS, 2002).

Com relação a distribuição de alimentos, é fato que essa ocorre de forma bastante desigual. Esse fato decorre dos padrões políticos e econômicos assumidos por cada país. A exemplo disto temos a gritante diferença na distribuição de alimentos em países desenvolvidos e em desenvolvimento (ABREU, 1995). No entanto, é importante mencionar que em alguns países desenvolvidos, embora haja uma abundância na distribuição de alimentos, estes não são nutricionalmente adequados (MONTEIRO, 2013).

\subsection{Segurança Alimentar x Insegurança Alimentar}

Todas as pessoas têm o direito há uma alimentação saudável, com qualidade e de fácil acesso de modo permanente. No entanto, nem todas as pessoas possuem condições de ter uma alimentação saudável e permanente, é este um dos casos em que se evidencia a insegurança alimentar (HOFFMANN, 1995; PESSANHA, 2016).

A segurança alimentar e nutricional (SAN) pode ser definida como o direito de todos ao acesso regular e permanente a alimentos de qualidade, em quantidade suficiente, sem comprometer o acesso a outras necessidades essenciais e que respeitem a diversidade cultural, sendo ambiental, cultural, econômica e socialmente sustentáveis (FAO, 2006).

Ao longo dos anos tem-se buscado formas de reduzir os problemas de insegurança alimentar e nutricional das nações, bem como, criar indicadores que auxiliem a mensurar essa fragilidade social (fome, desnutrição, más condições alimentares) que prejudica o acesso a uma alimentação saudável (KEPPLE, 2011).

Neste sentido, para controlar a insegurança alimentar é necessário identificar suas causas e sua localização é importante fazer uso dos indicadores válidos para manter a confiança mundial (SPERANDIO, 2018).

A insegurança alimentar está associada não só à baixa disponibilidade de alimentos, como também à vulnerabilidade social. Relaciona-se à estrutura da sociedade, ao mercado de trabalho e a características como idade, nível de escolaridade do chefe da 
família, situação econômica, desemprego, raça/cor e número de moradores nos domicílios (BARROS et al, 2020).

\subsection{Programa Nacional de Alimentação Escolar ou apenas Alimentação Escolar}

As escolas são fundamentais na formação de hábitos alimentares saudáveis, pois são locais privilegiados para se trabalhar atividades de promoção de alimentação saudável, visto seu papel educativo e sua função social (ZANCUL, 2008). Com a criação do Programa Nacional de Alimentação Escolar (PNAE), que atende os estudantes da educação básica: ensino fundamental, ensino médio e a modalidade de ensino de jovens e adultas (EJA); como também as escolas filantrópicas em todo o território nacional. O programa tem por objetivo principal a melhoria das condições nutricionais dos educandos, a melhoria do rendimento escolar, a formação de hábitos alimentares saudáveis, através de ações educacionais alimentares e nutricionais (SANTOS, 2015).

O Programa Nacional de Alimentação Escolar (PNAE), implantado em 1955, é um programa de cunho federal que, através da oferta da alimentação escolar e de ações de educação alimentar e nutricional, visa à contribuição do crescimento, do desenvolvimento, da aprendizagem, do rendimento escolar dos estudantes e da formação de hábitos alimentares saudáveis. O público atendido pelo Programa são os alunos de toda a educação básica (educação infantil, ensino fundamental, ensino médio e educação de jovens e adultos) matriculados em escolas públicas, filantrópicas e em entidades comunitárias (conveniadas com o poder público), por meio da transferência de recursos financeiros. O PNAE é considerado um dos maiores programas na área de alimentação escolar no mundo e é o único com atendimento universalizado (BRASIL, 2009a).

Mastroeni et al., (2013) em seu estudo sobre o consumo da refeição escolar na Rede Pública Municipal de Ensino, destacaram a importância da alimentação escolar principalmente para os alunos que são de condições socioeconômicas desfavoráveis, uma vez que grande parcela tem essa alimentação como a única refeição do dia. A alimentação escolar é uma forma de ter o acesso, mesmo que reduzido, a uma alimentação que possa combater a fome de forma imediata, o que também pode ser importante para se dinamizar a economia local, aumentando efeitos positivos sobre eixos importantes que a política pode afetar, como o desenvolvimento local, aproveitamento escolar e ampliação da segurança alimentar da população (BELIK et al., 2009). De acordo com Reis et al., (2011), o Programa Nacional de Alimentação Escolar (PNAE) é atuante para promover a 
segurança alimentar e nutricional, além de ser uma forma de contribuir ainda mais com o desempenho escolar, reduzindo assim a evasão escolar. Um planejamento de cardápio adequado é crucial para se atingir ao objetivo do programa, oferecendo o aporte nutricional mínimo e contribuindo para a formação de hábitos alimentares. O PNAE está inserido na Política Nacional de Segurança Alimentar e Nutricional (PNSAN), desde 2005, como um dos seus eixos estruturantes de acesso aos alimentos.

Segundo Carvalho e Castro (2009, p. 5),

A alimentação escolar envolve aspectos cultural-territoriais; interações socioeconômicas ambientais; político-institucionais; de respeito ao ciclo da natureza de ofertar alimentos para atender à necessidade básica do indivíduo de não sentir fome; entre outros, a fim de promover a Segurança Alimentar e Nutricional (SAN) e o Direito Humano à Alimentação Adequada (DHAA).

Nesse sentido, segurança alimentar e nutricional começam a ser entendidos como uma ferramenta para fomentar a soberania alimentar do país, com o incentivo aos mercados institucionais - Programa de Aquisição de Alimentos (PAA) e Programa Nacional de Alimentação Escolar (PNAE).

O PNAE estimula a agricultura familiar, uma vez que adquire alimentos para a alimentação escolar estabelecendo uma relação institucional entre a alimentação escolar e a agricultura familiar. Tratando de valorizar o agricultor, potencializar o desenvolvimento local, estreitar circuitos de comercialização, diminuir custos, aumentar a qualidade dos produtos e servir um alimento fresco, mais saudável e saboroso no prato dos alunos (BARROS et al., 2020).

Neste momento, por conta do isolamento social para o enfrentamento da pandemia da COVID-19, o PNAE se encontra frente a um enorme desafio para continuar com o fornecimento da alimentação escolar. Uma vez que as escolas estão com a aulas suspensas presencialmente trabalhando remotamente que significou a interrupção ou a precarização do acesso à alimentação, o que não apenas impacta no orçamento das famílias, mas também prejudica quantitativa e qualitativamente a alimentação dos alunos. As escolas municipais aderiram a preparar e entregar marmitas durante alguns dias da semana para as famílias dos alunos mais carentes. Assim, entendemos que o PNAE tem um papel importantíssimo no combate à insegurança alimentar e a fome durante a pandemia, de modo que necessitam de um conjunto de estratégias para serem adotadas dentro de um curto espaço de tempo (AMORIM, 2020).

\subsection{Desperdício de Alimentos}


A Organização das Nações Unidas para a Alimentação e Agricultura (FAO), elaborou o relatório Food wastage footprint: Impacts on natural resources (A pegada do desperdício de alimentos: impactos sobre recursos naturais), o qual afirma que o mundo desperdiça, anualmente, cerca de 1,3 bilhão de toneladas de alimentos. E os efeitos desse desperdício, causa prejuízos relevantes à sociedade, constatados em perdas econômicas, em contexto de redução da oferta e consequentemente aumento dos preços do produto. Acredita-se que as consequências econômicas diretas do desperdício de alimentos alcancem, aproximadamente, 750 bilhões de dólares anualmente. A FAO observou que a maior parte das perdas de alimentos ocorre nas fases de pós-produção, como colheita, transporte e armazenamento. Nos países em desenvolvimento, o desperdício dos alimentos existe devido à infraestrutura inadequada, já nos países mais desenvolvidos o problema acontece durante as fases de comercialização e consumo (FAO, 2013).

Estudos apontam que as perdas e desperdícios ocorrem por razões distintas. As prováveis causas estão relacionadas ao desconhecimento técnico na utilização de maquinários durante a produção e colheita dos alimentos, mal armazenamento, descuido durante o manuseio e não aceitabilidade na hora do consumo (FILHO, 1996, MARTINS; FARIAS, 2002).

A redução no desperdício de alimentos, seja em escolas ou em qualquer outro espaço de alimentação, representa uma opção de evitar os impactos gerados pela produção de alimentos, bem como, representa uma das principais ferramentas para combater a segurança alimentar (SANTOS, 2016).

Essa questão atenuaria os dados alarmantes que apontam para o aumento de $60 \%$ na necessidade de produção de alimentos até 2050 (ALEXANDRATOS; BRUINSMA, 2012).

Sendo assim, novos projetos são elaborados na política da segurança alimentar no Brasil, para amenizar as perdas e desperdícios no país (FAO, 2013; SANTOS, 2016).

Nas últimas décadas houve um aumento do desperdício alimentar, principalmente nos países desenvolvidos onde os alimentos são em fartura, custo acessível e fácil acesso. Com tudo o consumidor não usufrui com coerência (ARAUJO, 2017). O impacto que o desperdício causa na cadeia alimentar contribui para o aumento do consumo e da produção causando consequências serias para o meio ambiente. O Desperdício alimentar é um problema mundial que necessita ser investigado, estudado e pugnado (VARELA et al, 2015). 
Considera-se desperdício a perda de alimentos não utilizados, as refeições prontas e a sobra que fica nos pratos (CASTRO, 2003).

Como forma de reverter este cenário evidencia-se a necessidade de compreender os processos que levam ao desperdício, bem como, adequar a educação nutricional, no que tange ao preparo das refeições para garantir sua aceitabilidade (CASTRO, 2002).

É de extrema importância transmitir aos consumidores informações atuais e de fácil compreensão para motivar o combate ao desperdício alimentar, mostrando os benefícios ambientais e económicos dessa prevenção. Estas informações devem ser transmitidas de diferentes formas para atingir ao máximo de pessoas (como por exemplo em língua gestual). Uma forma de fazer sensibilizar e capacitar os alunos, desde o ensino primário até ao final da escolaridade obrigatória para o combate ao desperdício alimentar (MARQUES, 2020).

\section{METODOLOGIA DA PESQUISA}

O universo de estudo é um município do interior do Rio Grande do Sul denominado Dom Pedrito, localizado na Região da Campanha, cuja sede está situada com as coordenadas geográficas: Latitude $30^{\circ} 58^{\prime} 58^{\prime \prime} \mathrm{S}$, Longitude $54^{\circ} 40^{\prime} 23^{\prime \prime} \mathrm{W}$, Altitude 141m, Área territorial de 5194,8 Km2, fazendo divisa com os municípios de Lavras do Sul e Bagé (Nascimento et al., 2019). Segundo dados do IBGE (2010), Dom Pedrito é o quarto maior município do Estado em extensão, e uma população de 38.898 habitantes, e destes, 35.275 na zona urbana e somente 3.623 na zona rural, com 717 estabelecimentos familiares, totalizando uma área de 22.904 ha.

Figura 1- Mapa do estado do Rio Grande do Sul, Brasil com destaque no município de Dom Pedrito, ressaltado em cor verde. 


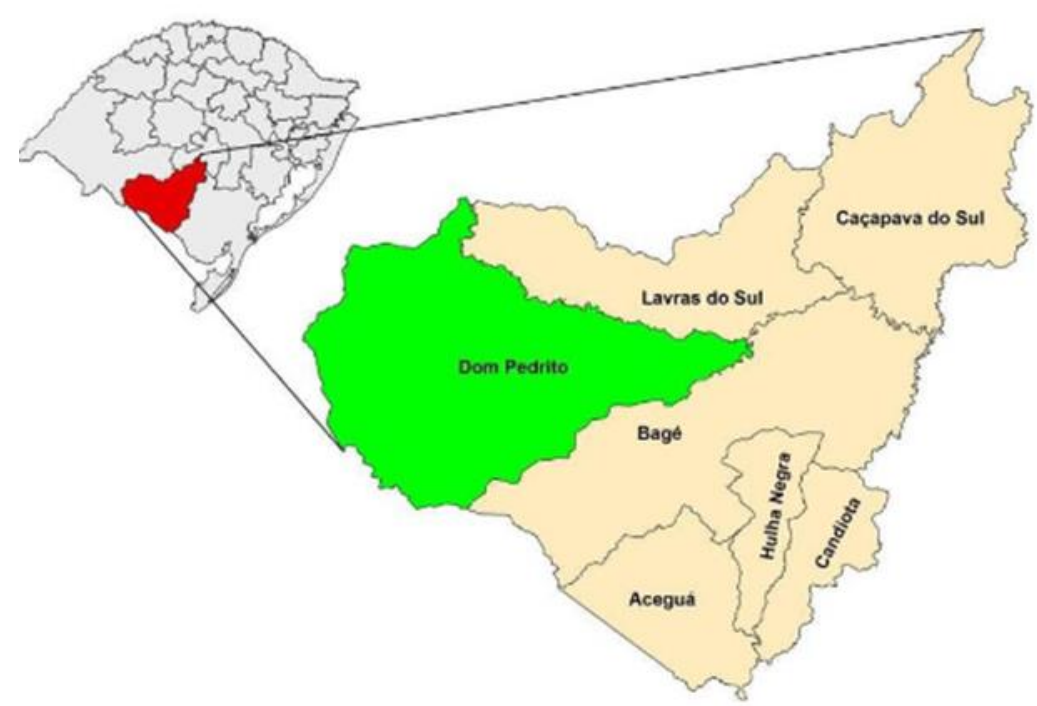

Fonte: Matte et al. (2015, p. 151).

O município de Dom Pedrito possui 8 (oito) escolas municípais urbanas e 2 (duas) escolas rurais, totalizando 10 escolas.

Foram alvo de estudo as diretoras e merendeiras das escolas municípais urbanas: EMEF Alcides Maia, EMEF Alda Seabra, EMEF Alexandre Viera, EMEF Argeny de Oliveira Jardim, EMEF Bernardino Tatu, EMEF Duque de Caxias, EMEF José Tude de Godoy, EMEF Herodiano Arrué e, as escolas rurais: EMREF Anna Riet Pinto e EMREF Sucessão dos Moraes.

Como técnica de coleta de dados foi utilizado um roteiro com questões fechadas e questões abertas, que abordou a percepção e comportamento dos educandos em relação a alimentação e desperdício de alimentos na alimentação escolar.

Após as imersões nas escolas, os dados foram organizados em planilhas eletrônicas do software de computador Excel. Os gráficos gerados abordaram os números absolutos bem como a frequência. A análise das questões subjetivas se deu através da análise textual de discurso, com a categorização das respostas (MORAIS; GALIAZZI, 2006).

\section{RESULTADOS E DISCUSSÃO}

As diretoras e merendeiras que participaram no estudo apresentaram uma idade média de 50 anos, sendo todas do sexo feminino (100\%). Dentre as diretoras, $56 \%$ estão 
na faixa etária entre 51 e 61 anos e as merendeiras com 50\% para a mesma faixa etária. A figura 2 apresenta os valores analisados nas escolas.

Figura 2- Faixa etária das respondentes.

\section{Diretoras}

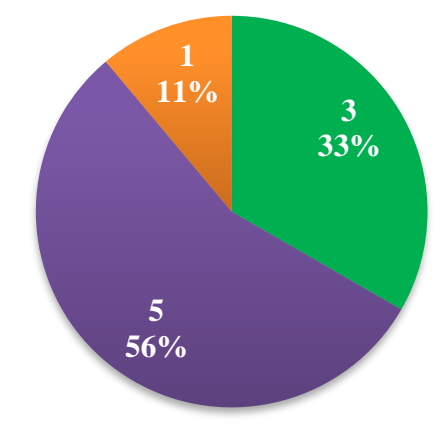

"41-50 घ51- $61 \quad$ NÃO REVELOU

\section{Merendeiras}

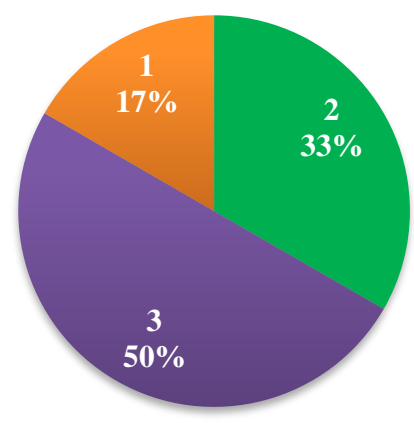

-41-50 $\square 51-61 \quad$ NÃO REVELOU

A figura 3 representa a informação de um dos fatores referentes ao desperdício, que é o consumismo.

Figura 3 - Abordagens referente ao consumismo e desperdício de alimentos respondidas pelas merendeiras e diretoras, a) Você considera que o consumismo é um dos fatores para o desperdício de alimentos? e b) Você vê casos de desperdício proposital de alimentos na sua escola?
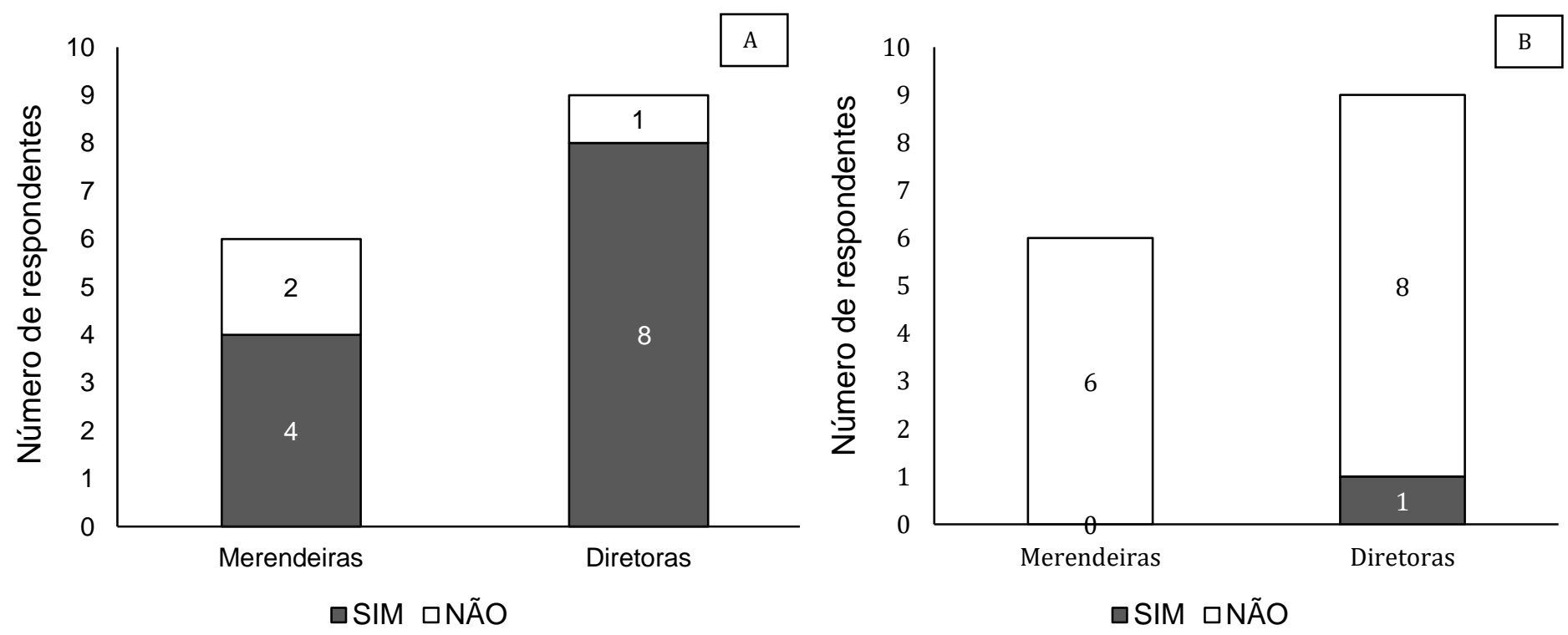
Analisando os gráficos percebemos que a maioria das diretoras e merendeiras acreditam que o consumismo é um fator de desperdício (Figura 3), em contrapartida as mesmas não veem desperdício proposital nas escolas. Segundo o desperdício de alimentos representa um problema ambiental e ético e tem repercussões sobre a fome, a redução da pobreza, a nutrição e o crescimento económico e social (FAO, 2012).

Ventura (2017), ao estudar o desperdício e suas relações verificou que um dos pontos que pesam na rejeição de algumas refeições está o fato de essas serem pouco apelativas em termos sensoriais, muitas vezes ocorrem em um espaço de tempo reduzido ou apresentam uma oferta inadequada de alimentos. Os itens mencionados pelo autor são corriqueiros em sociedades acostumadas ao desperdício e que não possuem como prioridade trabalhar o cuidado para que isso não aconteça (SAPHIRE, 1998).

Tabela 1 - Compilada de quatro (4) questões abordadas no instrumento de coleta de dados e suas respectivas representatividades de respostas, sendo 'sim' ou 'não'.

\begin{tabular}{|c|c|c|c|c|}
\hline \multirow{3}{*}{ Descrição da questão } & \multicolumn{4}{|c|}{ Respostas $\mathrm{n}^{\circ}=$ número } \\
\hline & \multicolumn{2}{|c|}{ Merendeiras } & \multicolumn{2}{|c|}{ Diretoras } \\
\hline & $\underset{\left(n^{\circ} ; \%\right)}{\operatorname{Sim}}$ & $\begin{array}{c}\text { Não } \\
\left(\mathrm{n}^{\mathrm{o}} ; \%\right)\end{array}$ & $\begin{array}{l}\operatorname{Sim} \\
\left(\mathrm{n}^{\mathrm{o}} ; \%\right)\end{array}$ & $\begin{array}{l}\text { Não } \\
\left(\mathrm{n}^{\mathbf{o}} ; \%\right)\end{array}$ \\
\hline $\begin{array}{l}\text { Você busca, conscientemente, evitar o } \\
\text { perdício de alimentos? }\end{array}$ & $6 ; 100$ & $0 ; 0$ & $9 ; 100$ & $0 ; 0$ \\
\hline $\begin{array}{l}\text { Você conscientiza seus colegas/alunos a } \\
\text { tar o desperdício? }\end{array}$ & $6 ; 100$ & $0 ; 0$ & $9 ; 100$ & $0 ; 0$ \\
\hline $\begin{array}{l}\text { Você sabe o destino dos resíduos } \\
\text { nentares produzidos na sua escola? }\end{array}$ & $6 ; 100$ & $0 ; 0$ & $9 ; 100$ & $0 ; 0$ \\
\hline
\end{tabular}

A pesquisa foi realizada com as diretoras e merendeiras das escolas com um questionário com perguntas para melhor direcionar a pesquisa.

Os cardápios de alimentação servidos nas escolas são elaborados pela nutricionista da Secretaria da Educação, sendo que as vezes adaptado pela merendeira da escola porque as vezes não é possível seguir o planejamento, por falta de produtos na hora do preparo. Porém, este setor está sempre disponível para sanar dúvidas e providenciar o que falta. Seguem as orientações tanto na teoria quanto na prática da alimentação saudável.

A origem dos alimentos utilizados no preparo da alimentação escolar é por licitações feitas pela Prefeitura e a Secretaria da Alimentação que realizam as compras e 
fazem a distribuição nas escolas, alguns produtos são adquiridos com produtores locais (agricultura familiar), como legumes, frutas e verduras e no comércio local.

O número de refeições servidas nas escolas do município são em torno de $150 \mathrm{a}$ 250 refeições diárias, com a pandemia 45 a 100 refeições são servidas em marmitas e entregues aos alunos carentes, cada escola estabelece um cronograma de entrega. Nas duas escolas rurais a merenda é diferenciada, duas vezes por semana é período integral, os alunos permanecem todo dia na escola, nestes dias, recebem café da manhã, almoço e lanche da tarde. Nos demais dias, recebem café da manhã e almoço.

Percebe-se o desperdício de alimentos gerados nas escolas quando as merendas são entregues em pratos já servidos aos alunos, sendo que a maioria mal toca na comida, ou também ao fazer a merenda em quantidade maior do que o número de alunos existentes que consomem estes alimentos.

Dificilmente sobra alimentos nas escolas, se tem muito cuidado com as quantidades elaboradas nas refeições, frutas sempre são servidas como sobremesa ou distribuídas aos alunos como merenda. As sobras limpas são reaproveitadas no dia seguinte ou doadas aos alunos carentes, as pequenas sobras nos pratos são destinadas aos animais, já as sobras de legumes e frutas são depositadas na composteira orgânica. Segundo Parisenti et al. (2008) é importante que se tenha um registro de sobras, devoluções e queixas sobre os alimentos servidos, pois isso pode contribuir para a adequação do cardápio oferecido aos consumidores, no caso estudantes.

\section{CONCLUSÃO}

Em suma, foi possível observar que nas escolas municipais de Dom Pedrito - RS, as diretoras e merendeiras têm consciência e evitam o desperdício de alimentos.

O tema voltado para o desperdício de alimentos é de grande relevância, que merece ser estudado mais a fundo, uma vez que não envolve apenas o custo, mas as questões socioambientais e políticas. Desta forma, tais fatores devem ser analisados e bem planejados a fim de minimizar os desperdícios alimentar dentro do universo escolar. Os profissionais, docentes e discentes precisam ser orientados sobre a problemática e incentivada sobre práticas ambientais e sociais mais sustentáveis, dessa forma, teremos uma sociedade mais consciente do ponto de vista social e ambiental. 


\section{REFERÊNCIAS}

ABREU, M. Alimentação Escolar na América Latina: programas universais ou focalizados/políticas de descentralização. Merenda Escolar. 1995, v.15, n. 67, jul.-set. Disponível em: http://www.inep.gov.br/cibec/linha

ALEXANDRATOS, N.; BRUINSMA, J. World Agriculture Towards. Revision ESA Workingpaper. $\mathrm{N}^{\circ} .12-03$ FAO, Rome, 2012.

ALTEMBURG, Shirley Grazieli Nascimento. A comida invisível: representações sociais sobre a alimentação escolar entre a comunidade escolar e os agricultores familiares na região de Pelotas, RS. 2014.

AMORIM, A. L. B. D., RIBEIRO JUNIOR, J. R. S.; BANDONI, D. H. Programa Nacional de Alimentação Escolar: estratégias para enfrentar a insegurança alimentar durante e após a COVID-19. Revista de Administração Pública, 54(4), 1134-1145, 2020.

ARAÚJO, L. R., Ada. Avaliação e controlo do desperdício alimentar em refeitórios escolares do Município de Barcelos. Acta Portuguesa de Nutrição, n. 8, p. 6-9, 2017.

BARROS, E. C. P. G., SGUAREZI, S. B., CARDOSO, K. E. H., FROEHLICH, A. G., RAMBO, J. R., LAFORGA, G., ... \& DE OLIVEIRA COSTA, M. Balanço de produção científica: operacionalização do programa nacional de alimentação escolar (PNAE) com agricultura familiar. Brazilian Journal of Development, 6(8), 55454-55471, 2020.

BARTOLAZZE, L. A., \& DE MELO CAZAL, M. Avaliação da composição nutricional e aceitabilidade da alimentação escolar. Revista Ciência em Extensão, 15(3), 7-17, 2019.

BELIK, W.; SOUZA, L. R. Algumas reflexões sobre os programas de alimentação escolar na América Latina. Planejamento e Políticas Públicas. n.33. jul./dez. 2009.

BOITO, T., HARTMANN, V., KÜMPEL, D. A., \& DE CARLI, G. Avaliação de Cardápios de uma escola de Educação Infantil. Revista Contexto \& Saúde, 19(36), 14 19, 2019.

CARVALHO, D. G.; CASTRO, V. M. O programa nacional de alimentação escolarPNAE como política pública de desenvolvimento sustentável. Centro de Desenvolvimento sustentável da Universidade de Brasília. Brasília - D.F., julho/2009.

CASTRO, M. D. A. S, Resto-Ingesta e aceitação de refeições em uma Unidade de Alimentação e Nutrição. Revista Higiene Alimentar, v. 17, n. 114-115, p. 24 - 28, 2003.

CASTRO, M. H. C. A. Fatores determinantes de desperdício de alimentos no Brasil: diagnóstico da situação. 2002. 93 p. Monografia (Especialização em Gestão de 
Qualidade em Serviços de Alimentação) - Universidade Estadual do Ceará, Fortaleza, 2002.

FAO. The State of Food and Agriculture [Internet]. Food and Agriculture Organization (FAO). Rome 2012 [cited 2017 Mar 15]. Available from: http://www.fao.org/3/a-i3028e.pdf.

FILHO, J.V.C. Transporte de produtos agrícolas sobre a questão de perdas. Revista da economia e Sociologia Rural. Vol 39. N3 e 4. pg. 173-199. 1996.

FOOD AND AGRICULTURE ORGANIZATION (FAO). The state of food insecurity in the world 2006: Eradicating World hunger - taking stock ten years after the World Food Summit. Rome: FAO; 2006.

HOFFMANN, R. Pobreza, insegurança alimentar e desnutrição no Brasil. Estudos avançados, v. 9, n. 24, p. 159-172, 1995.

KEPPLE AW, Segall-Corrêa AM. Conceituando e medindo segurança alimentar e nutricional. Ciência Saúde Colet. 2011; 16(1):187-99.

MALUF, R. Segurança alimentar e nutricional. Petrópolis: Vozes, 2007.

MARQUES, J. P. B. Avaliação do conhecimento de desperdício alimentar em crianças do $1^{\circ}$ ciclo do ensino básico. Dissertação de Mestrado. Escola Superior de Educação e Ciências Sociais. Especialização em Educação e Desenvolvimento Comunitário, 2020.

MASTROENI, M. F; MASTROENI, S. S. B.; MOTA, C. H. Consumo da refeição escolar na rede pública municipal de ensino. Revista. Bras. Est. pedag., Brasília, v. 94, n.236, p.168- 184, jan./abr. 2013.

MATTE, A.; SPANEVELLO, R. M.; ANDREATTA, T. Perspectivas de sucessão em propriedades de pecuária familiar no município de Dom Pedrito-RS. Holos, vol. 1, p. $151,2015$.

MONTEIRO, C.A. A dimensão da pobreza, da fome e da desnutrição no Brasil. In: RESTAURANT, A. POPULAR. Redução do desperdício de alimentos em um restaurante popular. Revista Brasileira de Tecnologia, v. 7, n. 02, p. 1106-1117, 2013.

MORAES, R.; GALIAZZI, M.C. Análise textual discursiva: processo reconstrutivo de múltiplas faces. 2006.

NASCIMENTO, S. G. S., VERDUM, A. H., HANKE, D., BECKER, C., \& de ÁVILA, M. R. Consumo Verde: uma análise sobre o comportamento ambiental dos consumidores de Dom Pedrito (Rio Grande do Sul- Brasil). Revista Brasileira de Meio Ambiente, 7(1), 2019. 
NASCIMENTO, S. G., BECKER, C., DA SILVA, F. N., CALDAS, N. V., \& DE ÁVILA, M. R. Produção agroecológica e segurança alimentar e nutricional (Brasil). Revista de Ciências Agrárias, 42(1), 294-304, 2019.

PARISENTI, J.; FIRMINO, C.C.; GOMES, C.E. Avaliação de sobras de alimentos em unidade produtora de refeições hospitalares e efeitos da implantação do sistema de Hotelaria. Alimentos e Nutrição, v. 19, n. 2, p. 191-194, 2008.

PESSANHA, Lavínia; VANNIER-SANTOS, Cristina; MITCHELL, Paulo Vicente. Indicadores para avaliar a Segurança Alimentar e Nutricional e a garantia do Direito Humano à Alimentação: metodologias e fontes de dados. Anais, p. 1-21, 2016.

REIS, C. E. G.; VASCONCELOS, I. A. L.; BARROS, J. F. N.; Políticas públicas de nutrição para o controle da obesidade infantil. Rev. Paul Pediatr. v.29, n.4, p. 33-625, 2011.

SANCHES, Y. N. A.; SALLA, H. Conscientização sobre desperdício na escola. In: I SECITEC - Semana de Educação, Ciência e Tecnologia, 2010.

SANTOS, Juciene Almeida dos. Desperdício de alimentos em restaurantes universitários no Brasil. 2016. Trabalho de Conclusão de Curso. Universidade Federal do Rio Grande do Norte.

SANTOS, Natanael Antonio dos; ACCIOLY DE SOUZA, Thaisa; SOUZA, Maria de Fátima de. Intervenção no desperdício da merenda em uma escola no interior do estado do Rio Grande do Norte, Brasil. AmbientalMente Sustentable: Revista científica galego-lusófona de educación ambiental, p. 1139-1152, 2015.

SAPHIRE, David.SAPHINRE D. GETTING AN "A" AT LUNCH - Smart strategies to reduce waste in campus dining. New York, USA: Inform; 1998.Disponívelem: < http://infohouse.p2ric.org/ref/04/03993.pdf>Acessoem: 16 outubro 2019.

SILVA, Marcondes Viana. Avaliação da adesão e aceitabilidade dos cardápios do Programa de Alimentação Escolar em escolas municipais de Itapetinga-BA: indicadores de desperdício de alimentos. Revista eletrônica em Gestão, Educação e Tecnologia Ambienta, v.20, n. 1, p. 73-85, 2016.

SPERANDIO, Naiara; MORAIS, Dayane de Castro; PRIORE, Silvia Eloiza.Escalas de percepção da insegurança alimentar validadas: a experiência dos países da América Latina e Caribe. Ciência \& Saúde Coletiva, v. 23, p. 449-462, 2018.

TONHÃO, K. E., \& DA SILVA MANCA, R. O custo ambiental do desperdício de alimentos de origem vegetal e animal: proposta de uma valoração com base em tarifas existentes. Interciência \& Sociedade, 5(1), 2020.

VALENTE, Flávio Luiz Schieck. Fome, desnutrição e cidadania: inclusão social e direitos humanos. Saúde e sociedade, v. 12, p. 51-60, 2003. 
VARELA, M. C. M. S.; CARVALHO, D. R.; OLIVEIRA, R. M. A.; DANTAS, M. G. $S$. $O$ custo dos desperdícios: um estudo de caso no restaurante universitário da Universidade Federal do Rio Grande do Norte. XXII Congresso Brasileiro de Custos - Foz do Iguaçu, PR, Brasil, 2015.

VARELLA, C. A. A. Análise Multivariada Aplicada as Ciências Agrárias: Análise de Componentes Principais. Universidade Federal Rural do Rio de Janeiro - UFRRJ. Seropédica - RJ, 2008.

VAZ, C. S. Restaurantes - controlando custos e aumentando lucros. Brasília, 2006. 196 p. Anais do XIX EAIC - 28 a 30 de outubro de 2010, UNICENTRO, Guarapuava PR.

VENTURA, Rafaely De Sousa. Desperdício De Alimento Nas Escolas: 2017. 33

Folhas. Trabalho De Conclusão De Curso De Graduação Em Nutrição - Faculdade Anhanguera, Guarulhos - 2017.

ZANCUL, Mariana de Senzi; DUTRA DE OLIVEIRA, José Eduardo. Considerações sobre ações atuais de educação alimentar e nutricional para adolescentes. Alimentos e Nutrição Araraquara, v. 18, n. 2, p. 223-227, 2008. 


\section{Anexos}

Escola:

Nome:

Cargo:

Sexo: Masculino ( ) Feminino ( ) Idade:

Moradia: Zona Urbana ( ) Zona Rural ( )

1 - Você busca, conscientemente, evitar o desperdício de alimentos?

Sim ( ) Não ( )

2 - Você conscientiza seus colegas/alunos a evitar o desperdício?

Sim ( ) Não ( )

3 - Você vê casos de desperdício proposital de alimentos na sua escola?

Sim ( ) Não ( )

4 - Você sabe o destino dos resíduos alimentares produzidos na sua escola?

Sim ( ) Não ( )

5- Você considera que o consumismo é um dos fatores para o desperdício de alimentos? Sim ( ) Não ( )

1 - Como são elaborados os cardápios de alimentação servida nas escolas?

2- Qual a origem dos alimentos utilizados no preparo da alimentação escolar? Se possível indique o nome das empresas.

3- Qual o número de refeições servidas nas escolas do município?

4 - Como você percebe o desperdício de alimentos gerado nas escolas?

5- Você qual destino é dado aos resíduos e as sobras limpas da escola?

Aplicar para: nutricionistas do município, secretário de educação, merendeiras e diretoras.

\section{Respostas das diretoras:}

1 - Como são elaborados os cardápios de alimentação servida nas escolas?

É elaborado pela nutricionista da secretaria da educação, sendo que as vezes adaptado pela merendeira da escola porque nem sempre é possível seguir este planejamento, por falta de produto na hora do preparo. Porém, este setor está sempre disponível para sanar dúvidas e providenciar o que falta. Seguimos orientações tanto na teoria quanto na prática, da alimentação saudável.

2- Qual a origem dos alimentos utilizados no preparo da alimentação escolar? Se possível indique o nome das empresas. 
As licitações são feitas pela prefeitura e a secretaria da alimentação realiza as compras e faz a distribuição nas escolas, alguns produtos são adquiridos com produtores locais (agricultura familiar), como legumes, frutas e verduras e no João das Frutas.

3- Qual o número de refeições servidas nas escolas do município?

Cerca de 150 a 250 refeições são servidas diariamente, com a pandemia 45 á 100 refeições são servidas em marmitas e entregue aos alunos carentes cada escola estabelece um cronograma de entrega.

Nas duas escolas rurais a merenda é diferenciada, duas vezes por semana é período integral os alunos permanecem todo dia na escola; nestes dias, recebem café da manhã, almoço e lanche da tarde. Nos demais dias, recebem café da manhã e almoço.

4 - Como você percebe o desperdício de alimentos gerado nas escolas?

O desperdício pode-se dar quando as merendas são entregues em pratos já servidos aos alunos, sendo que muitos mal tocam na comida; ou também ao fazer a merenda em quantidade maior do que o número de alunos que consomem estes alimentos.

5 - Você qual destino é dado aos resíduos e as sobras limpas da escola?

Dificilmente sobra alimentos nas escolas; temos muito cuidado com as quantidades elaboradas nas refeições. Frutas sempre são servidas como sobremesa ou distribuídas aos alunos. Quando sobra reaproveitam no dia seguinte ou doam para os alunos carentes, as pequenas sobras dos pratos, são doadas a animais, já as sobras de legumes e frutas são depositadas na composteira.

\section{Respostas das merendeiras}

1 - Como são elaborados os cardápios de alimentação servida nas escolas? Elaborados pela Nutricionista da Prefeitura Municipal, contudo atualmente fazem a merenda conforme as crianças gostam de comer.

2- Qual a origem dos alimentos utilizados no preparo da alimentação escolar? Se possível indique o nome das empresas.

Hort fruti e da agricultura familiar e industrializados

3 - Qual o número de refeições servidas nas escolas do município?

Com a pandemia algumas escolas servem 100 refeições três vezes na semana. Nas escolas rurais dois dias da semana que os alunos permanecem todo dia na escola; nestes dias, recebem café da manhã, almoço e lanche da tarde. Nos outros é uma refeição.

4 - Como você percebe o desperdício de alimentos gerado nas escolas? Não há desperdício na escola porque as sobras são reaproveitadas e as vezes as crianças levam para casa.

5- Você qual destino é dado aos resíduos e as sobras limpas da escola?

São reaproveitados no dia seguinte e o que não serve para consumo vai pra os cachorros. 